\title{
Strap repairs using embedded patches: numerical analysis and experimental results
}

\author{
A.M.G. Pinto, R.D.S.G. Campilho, I.R. Mendes and A.P.M. Baptista
}

\begin{abstract}
Adhesively bonded repairs offer an attractive option for repair of aluminium structures, compared to more traditional methods such as fastening or welding. The single-strap (SS) and double-strap (DS) repairs are very straightforward to execute but stresses in the adhesive layer peak at the overlap ends. The DS repair requires both sides of the damaged structures to be reachable for repair, which is often not possible. In strap repairs, with the patches bonded at the outer surfaces, some limitations emerge such as the weight, aerodynamics and aesthetics. To minimize these effects, SS and DS repairs with embedded patches were evaluated in this work, such that the patches are flush with the adherends. For this purpose, in this work standard SS and DS repairs, and also with the patches embedded in the adherends, were tested under tension to allow the optimization of some repair variables such as the overlap length $\left(L_{\mathrm{O}}\right)$ and type of adhesive, thus allowing the maximization of the repair strength. The effect of embedding the patch/patches on the fracture modes and failure loads was compared with finite elements (FE) analysis. The FE analysis was performed in ABAQUS ${ }^{\circledR}$ and cohesive zone modelling was used for the simulation of damage onset and growth in the adhesive layer. The comparison with the test data revealed an accurate prediction for all kinds of joints and provided some principles regarding this technique.
\end{abstract}

\section{Keywords}

strap repairs; structural adhesive; experimental testing; finite element method

\section{Introduction}

Adhesively bonded techniques offer an attractive option for repair of aluminium structures, compared to more traditional methods such as fastening, riveting or welding, due to the reduction in stress concentrations, reduced weight and easy manufacturing/automation. As a result of the improvement in the mechanical characteristics of adhesives, adhesive bonding has progressively replaced the traditional joining methods, allowing a big step towards stronger and lighter unions between components.

There are several bonded repair configurations, for example, single-strap (SS), doublestrap (DS) and scarf. The SS repair is carried out after the structure undergoes damage at an intermediate section. The damage is subsequently removed by drilling a hole in the damaged 

region, and a circular patch is adhesively bonded on one of the structure faces, concentric with the drilled hole. Alternatively, the two-dimensional simplification involves repairing two rectangular plates separated by a fixed distance by adhesively bonding a rectangular patch on one of the plate's faces. SS repairs are easy to execute, but the eccentricity of the transmitted load, which leads to a significant deflection in the repair region and consequent peel peak stresses at the overlap edges [1]. These, added to the shear peak stresses developing in the same regions due to the differential straining of the repair constituents [2], are responsible for the small efficiency and temporary character of SS repairs. Consequently, this repair technique is usually not used in highly stressed or high responsibility structures or as a permanent repair. The DS repair technique is based on the same geometry, but it involves bonding two patches, one on each face of the damaged structure or plates. The DS repair procedure may not be straightforward to execute, depending on the access to both structure faces [3]. In this situation, partial disassembly of the component to be repaired may be required. Other limitations emerge such as the weight, aerodynamic performance and aesthetics. DS repairs are more efficient than the SS repair, due to the duplication of the adhesive shear area and the suppression of the transverse deflection of the adherends, since it is under symmetrical loads [2]. This reduces peel peak stresses and significantly enhances the repair strength. Shear stresses also become more uniform along the bond length as a result of smaller differential straining effects. Nonetheless, Marques and da Silva [4] showed that stress concentrations still exist at the edges, where cracks are prone to initiate. The scarf technique consists of the damaged material removal by drilling a conical hole with a pre-determined angle. The patch has the complementary shape of the drilled geometry and it is adhesively bonded to the structure. Compared with strap repairs, scarf repairs have the advantages of a higher efficiency and the absence of aerodynamic disturbance. Therefore, they are often used as a permanent repair, since they usually restore the undamaged strength of structures. The higher efficiency is caused by the elimination of the significant joint eccentricities of strap repairs, which act as stress raisers along the loading paths. Moreover, stress distributions along the bond length are more uniform, due to the tapering effect at the scarf edges [5]. The main disadvantages of this technique are the difficult machining of the surfaces, associated costs and requirement of specialized labour.

Many reports have been published regarding the influence of geometric changes and material modifications in adhesively bonded structures, in order to reduce the peak stresses and increase their strength [6-9]. Material modifications mainly attempt to optimize the material stiffness along the overlap to suppress stress concentrations at the overlap edges $[4,10-$ 14]. One of these techniques consists in the use of bi-adhesives along the bondline. By using a stiffer adhesive in the inner overlap region than at the edges, a larger amount of load is transmitted by the inner region of the bond and the joint strength increases, especially for brittle adhesives [15-17]. Young's modulus $(E)$ grading of the adherends is another alternative. Ganesh and Choo [18] evaluated grading of $E$ for the adherends in single-lap joints under tension to reduce stress concentrations. FE simulations showed that shear peak stresses in the adhesive layer diminished up to $20 \%$, increasing the load transfer at the overlap central region. Peel stresses were not affected by this modification, while longitudinal axial stresses slightly increased. Pinto et al. [19] showed by an FE stress and failure analysis that increasing the stiffness of the adherends materials in single-lap joints leads to a reduction in the joint bending, which, in turn, diminishes stresses at the overlap edges and, consequently, increases the strength of the joints. One of the most widespread techniques to suppress the concentrations of stresses is the use of adhesive fillets at the overlap edges. Fillets allow the redistribution of stresses in the mentioned regions and, as a result, they increase the strength of bonded unions [20-27]. For maximum effect of this modification, i.e. minimizing peel and shear peak 
stresses at the overlap edges, fillets should comprise all the patch thickness [28]. Rispler et al. [29] used an FE optimization iterative method to ascertain the optimal fillet shape in carbonepoxy tabs reinforced with adhesively bonded titanium plates. A $45^{\circ}$ straight fillet was found to be the optimal solution for the particular geometry tested. A theoretical and experimental study was carried out by Adams et al. [30] on the tensile strength of carbon-epoxy/steel double-lap joints, including several geometric changes, such as filleting the plate edges or chamfering the inner and outer adherends faces. An inside taper in the outer adherends combined with an adhesive fillet proved to be most efficient. Among the tested fillet angles $\left(17^{\circ}, 30^{\circ}\right.$ and $45^{\circ}$ ), the $30^{\circ}$ one was found to be the best solution. Overall, the theoretical predictions of the failure loads were accurate. Hildebrand [31] studied different shapes of adhesive fillet, reverse tapering of the adherend, rounding edges and denting in order to increase the joint strength. The influence of the joint-end geometry was evaluated for different metal adherend/ fibre-reinforced plastics adherend/adhesive combinations. The results of the numerical predictions suggested that with a careful joint-end design the strength of the joints could be increased by $90-150 \%$.

Sancaktar and Lawry [32] evaluated the use of single-lap joints with pre-bent adherends by photoelasticity, considering resin adherends bonded with liquid plastic cement. Experimental testing revealed that for the joint materials selected for the study, the failure strength of the joints could be increased up to $71 \%$, compared with the flat joint. Fessel et al. [33] performed an experimental and FE work regarding tensile loaded steel single-lap joints, with emphasis on wavy, improved wavy and reverse-bent geometries. These three modifications diminished peel and shear peak stresses at the overlap edges. The experimental tests showed strength improvements for the reverse-bent joint from 9 to $40 \%$, compared to a flat single-lap joint.

Although, there are several reports on the effect of geometric and/or materials changes to improve the strength of adhesive joints or strap repairs, very few studies deal with SS and DS repairs with embedded patches, such that these are completely flush with the adherends. Çitil et al. [34] studied the effects of embedding the patches on DS repairs. The effects of embedding patches on the failure loads and stress distributions were investigated experimentally and numerically. The repairs were made of aluminium adherends with four different thicknesses and the patches consisted of spring steel with different thicknesses and overlap lengths. It was seen from the results that the adherend and patch thickness, and also the overlap length had considerable influence on the failure loads and stress distributions.

In this work, standard SS and DS repairs, and also with embedded patches in the adherends, were tested under tension to allow the geometry optimization, by varying $L_{\mathrm{O}}$, thus allowing the maximization of the repairs strength. Tests were made with two adhesives: a brittle and a ductile one. A two-dimensional approximation to the strap repair geometry was considered, for design purposes. The influence of the patch embedding technique, showing advantages such as aerodynamic or aesthetics, was compared in strength with standard strap repairs, for the viability analysis of its implementation.

\section{Experimental work}

\subsection{Materials}

The adherends were cut from aluminium plates (commercial designation AA6082 T651) and the patches were fabricated from thin low carbon steel sheets. Two structural epoxy adhesives (Araldite ${ }^{\circledR} 2015$ and Araldite ${ }^{\circledR}$ AV138) were selected. The specified aluminium alloy was chosen due to its wide use in Europe for several structural applications under different extruded and laminated shapes. This aluminium alloy was previously characterized [35] using dogbone 
Table 1. Properties of the adhesives Araldite ${ }^{\circledR}$ AV138 and 2015 [37,38].

\begin{tabular}{lcc}
\hline Property & AV138 & 2015 \\
\hline Young's modulus, $E(\mathrm{GPa})$ & $4.89 \pm 0.81$ & $1.85 \pm 0.21$ \\
Poisson's ratio, $\mathrm{v}^{\mathrm{a}}$ & 0.35 & 0.33 \\
Tensile yield strength, $\sigma_{\mathrm{y}}(\mathrm{MPa})$ & $36.49 \pm 2.47$ & $12.63 \pm 0.61$ \\
Tensile failure strength, $\sigma_{\mathrm{f}}(\mathrm{MPa})$ & $39.45 \pm 3.18$ & $21.63 \pm 1.61$ \\
Tensile failure strain, $\varepsilon_{\mathrm{f}}(\%)$ & $1.21 \pm 0.10$ & $4.77 \pm 0.15$ \\
Shear modulus, $G(\mathrm{GPa})$ & $1.56 \pm 0.01$ & $0.56 \pm 0.21$ \\
Shear yield strength, $\mathrm{T}_{\mathrm{y}}(\mathrm{MPa})$ & $25.1 \pm 0.33$ & $14.6 \pm 1.3$ \\
Shear failure strength, $\mathrm{T}_{\mathrm{f}}[\mathrm{MPa}]$ & $30.2 \pm 0.40$ & $17.9 \pm 1.8$ \\
Shear failure strain, $\mathrm{V}_{\mathrm{f}}(\%)$ & $7.8 \pm 0.7$ & $43.9 \pm 3.4$ \\
\hline
\end{tabular}

${ }^{a}$ Manufacturer's data.

specimens. The stress-strain $(\sigma-\varepsilon)$ plots, obtained through tensile testing following the specifications in the ASTM-E8 M-04 standard [36], showed a nearly elastic-perfectly plastic behaviour with the following mechanical properties (average values and deviation): Young's modulus $(E)=70.07 \pm 0.83 \mathrm{GPa}$, tensile yield stress $\left(\sigma_{\mathrm{y}}\right)$ of $261.67 \pm 7.65 \mathrm{MPa}$, tensile failure strength $\left(\sigma_{\mathrm{f}}\right)$ of $324 \pm 0.16 \mathrm{MPa}$ and tensile failure strain $\left(\varepsilon_{\mathrm{f}}\right)$ of $21.70 \pm 4.24 \%$. The low carbon steel selected for the patches is characterized by a good weldability, ductility and low cost. This material was also subjected to tensile characterization, giving the following results: $E=204.23 \pm 2.10 \mathrm{GPa}, \sigma_{\mathrm{y}}=240.11 \pm 5.98 \mathrm{MPa}, \sigma_{\mathrm{f}}=340.98 \pm 4.67 \mathrm{MPa}$ and $\varepsilon_{\mathrm{f}}=38.90 \pm 3.81 \%$.

Due to the patch dimensions and ductility of the steel used, it will eventually undergo plastic deformation. The two adhesives selected for this work, Araldite ${ }^{\circledR}$ AV138 and Araldite ${ }^{\circledR}$ 2015, were previously characterized in tension and shear for the determination of all relevant parameters such as $E$, shear modulus $(G), \sigma_{\mathrm{y}}, \sigma_{\mathrm{f}}$ and $\varepsilon_{\mathrm{f}}[37,38]$. Table 1 summarizes the previously collected data on these adhesives (the value of $\sigma_{\mathrm{y}}$ was computed considering a plastic deformation limit of $0.2 \%$ for both adhesives). The results from these tests showed a brittle behaviour for the Araldite ${ }^{\circledR} \operatorname{AV} 138\left(\varepsilon_{\mathrm{f}} \approx 1.2 \%\right.$ and shear failure strain, $\mathrm{Y}_{\mathrm{f}}$, of approximately $7.8 \%)$ and a largely ductile behaviour for the Araldite ${ }^{\circledR} 2015\left(\varepsilon_{\mathrm{f}} \approx 4.8\right.$ and $\left.\gamma_{\mathrm{f}} \approx 44 \%\right)$, with a high degree of plasticization at a constant stress prior to failure. The failure strength of Araldite ${ }^{\circledR}$ AV138 adhesive was nearly two times that of Araldite ${ }^{\circledR} 2015$.

\subsection{Joint geometries and test conditions}

Figure 1 presents the repair geometries tested in this work: SS repairs without embedded patch (a) and with embedded patch (b), and DS repair without embedded patches (c) and with embedded patches (d). The main parameters are the length between gripping points $(200 \mathrm{~mm})$, the adhesive thickness $(0.2 \mathrm{~mm})$, the thickness of the adherends $(4 \mathrm{~mm})$ and patches $(1 \mathrm{~mm})$, and the width of the adherends and patches $(25 \mathrm{~mm})$. Three values of $L_{\mathrm{O}}$ were studied $(10,20$ and $30 \mathrm{~mm})$ comprising all the repair geometries. For the repairs with embedded patches, the overlap region of the adherends was milled up to a depth of $1.2 \mathrm{~mm}$ (patch + adhesive thickness) before bonding (Figure 1(b) and (d)). The bonding surfaces of the aluminium adherends and steel patches were cleaned with acetone and then grit-blasted with corundum sand. After the mechanical process of grit blasting to remove the surface oxide layer and contaminants, the surfaces were cleaned again with acetone, and allowed to dry before application of the adhesive. The repairs were fabricated manually, using a device developed to align the adherends and the patch. The bonding procedure consisted of the application of one patch at a time (for the DS repairs) with respective alignment and 
(a)

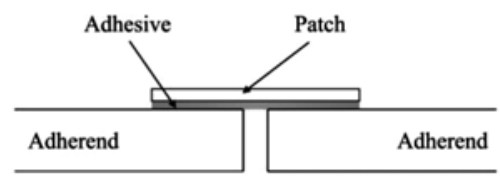

(c)

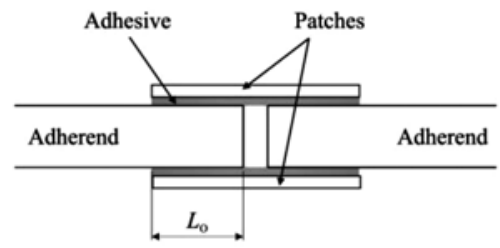

(b)
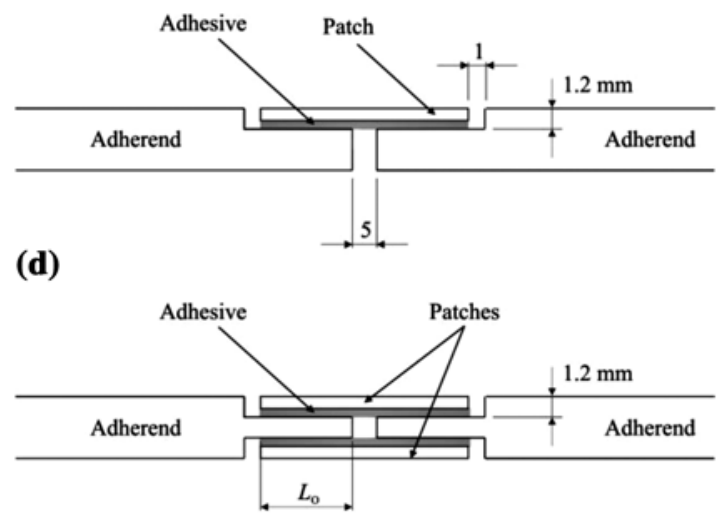

(dimensions in $\mathrm{mm}$ )

Figure 1. SS repair (a) no embedded patch; (b) embedded patch and DS repair (c) no embedded patches; and (d) embedded patches.

application of pressure with grips, followed by curing at room temperature for at least $12 \mathrm{~h}$ prior to removal from the device and bonding of the 2nd patch. The desired value of adhesive thickness $(0.2 \mathrm{~mm})$ was achieved with a calibrated wire (diameter of $0.2 \mathrm{~mm}$ ) at the patch edges. Before complete curing the excess adhesive at the overlap ends was completely removed manually for identical conditions among all tested specimens. Figure 2 shows some examples of SS and DS repair specimens with and without embedded patches, ready for testing.

(a)

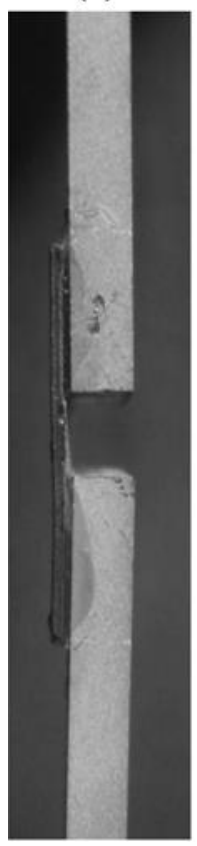

(b)

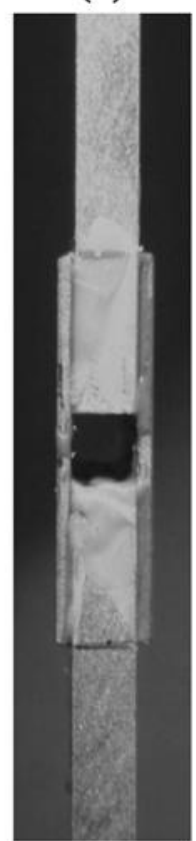

(c)

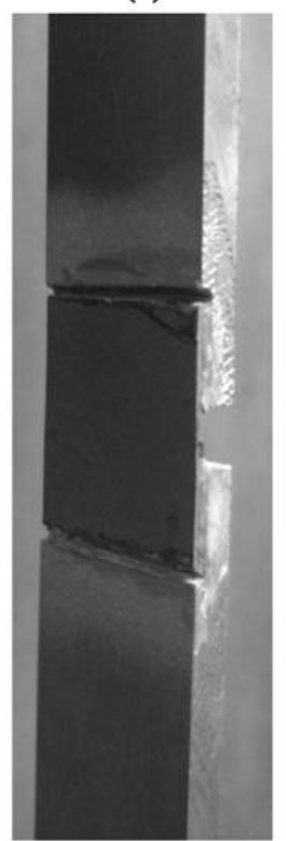

(d)

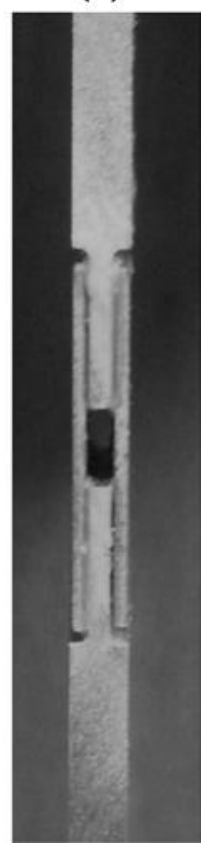

Figure 2. Strap repairs without embedded patches: SS (a) and DS (b); and with embedded patches: SS (c) and DS (d). 


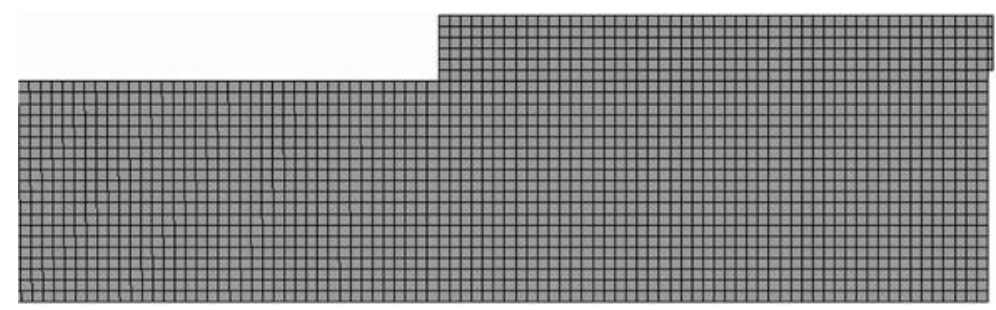

Figure 3. Mesh details at the overlap for the $L_{O}=10 \mathrm{~mm}$ adhesively bonded models (view of the symmetry plane).

After the joints fabrication, one week was allowed before testing for complete curing of the adhesive. The tests were carried out in a Shimadzu AG-X 100 testing machine equipped with a $100 \mathrm{kN}$ load cell, at room temperature and under displacement control $(1 \mathrm{~mm} / \mathrm{min})$. The reported test values for each condition are the average of four valid tests.

\section{Numerical analysis}

\subsection{Analysis conditions}

The FE analysis performed in ABAQUS®/standard accounted for geometrical non-linearities, because of the joint deflections that take place mostly in the SS joints [5]. The joints were fully modelled by the triangular CZM laws presented in Section 3.2, and the analyses were carried out by two-dimensional models (plane-strain conditions), which is acceptable considering the repairs geometry (Figure 1). Figure 3 shows a typical mesh for SS repair with $L_{\mathrm{O}}=10 \mathrm{~mm}$. The models used 4-node quadrilateral solid elements (CPE4 from ABAQUS®) and $\mathrm{COH} 2 \mathrm{D} 4$ 4-node cohesive elements. The joints were clamped at one of the edges, while the other edge was subjected to a tensile displacement concurrently with transverse restraining, to simulate real test conditions $[39,40]$. The thin adhesive layer was modelled by a single row of cohesive elements [41] incorporating a mixed-mode traction-separation law between the element faces, including the stiffness of the adhesive layer, as defined further in this work. The proposed modelling technique is currently implemented within ABAQUS® CAE suite and will be briefly described in the following.

\subsection{Cohesive zone modelling}

CZM are based on a relationship between stresses and relative displacements (in tension or shear). connecting paired nodes of cohesive elements (Figure 4), to simulate the elastic behaviour up to the cohesive strength ( $t^{0}$ in tension or $t^{0}$ in shear) and subsequent softening, to model the degradation of material properties up to failure. The shape of the softening region can also be adjusted to conform to the behaviour of different materials or interfaces [42]. The areas under the traction-separation laws in tension or shear $\left(G_{\mathrm{n}}\right.$ or $G_{\mathrm{s}}$, respectively) are equalled to the fracture toughness in tension $\left(G_{n}^{\mathrm{c}}\right)$ or in shear $\left(G_{s}^{\mathrm{c}}\right)$, by the respective order. Under pure loading, damage grows at a specific integration point when stresses are released in the respective damage law. Under a combined loading, stress and energetic criteria are often used to combine tension and shear [35]. The triangular law (Figure 4) assumes an initial linear elastic behaviour followed by linear degradation. Elasticity is defined by a constitutive matrix $(\mathrm{K})$, containing the stiffness parameters and related stresses and strains across the interface [43]. 


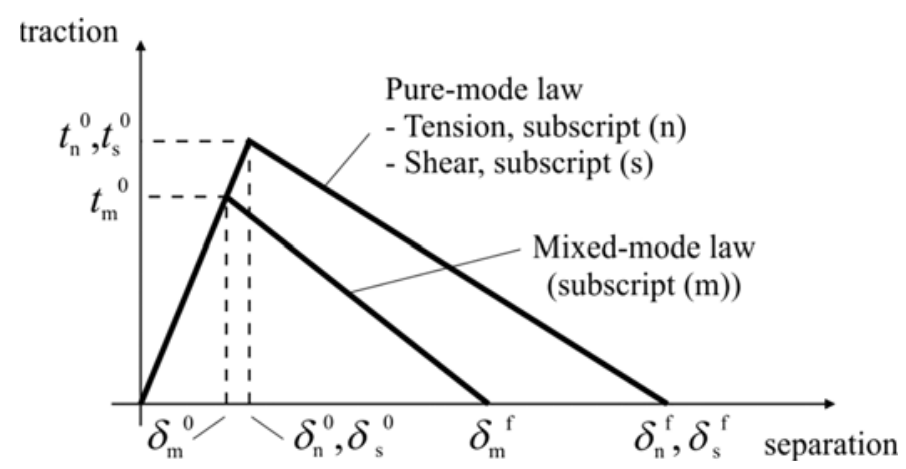

Figure 4. Traction-separation law with linear softening law available in ABAQUS®.

$$
t=\left\{\begin{array}{l}
t_{n} \\
t_{s}
\end{array}\right\}=\left[\begin{array}{ll}
K_{n n} & K_{n s} \\
K_{n s} & K_{s s}
\end{array}\right] \cdot\left\{\begin{array}{l}
\epsilon_{n} \\
\epsilon_{s}
\end{array}\right\}=K \varepsilon
$$

A suitable approximation for thin adhesive layers [42] is provided with $K_{n n}=E, K_{s s}=G$ and $K_{n s}=0$. Damage initiation can be specified by different criteria. In this work, the quadratic nominal stress criterion was considered for the initiation of damage, already shown to give accurate results [5] and expressed as [43]

$$
\left\{\frac{\left\langle t_{n}\right\rangle}{t_{n}^{0}}\right\}^{2}+\left\{\frac{t_{s}}{t_{s}^{0}}\right\}^{2}=1
$$

h i are the Macaulay brackets, emphasizing that a purely compressive stress state does not initiate damage [44]. After the mixed-mode cohesive strength is attained $\left(t_{\mathrm{m}}{ }^{0}\right.$ in Figure 4$)$ by the fulfilment of Equation (2), the material stiffness is degraded. Complete separation is predicted by a linear power law form of the required energies for failure in the pure modes [43].

$$
\frac{G_{\mathrm{n}}}{G_{\mathrm{n}}^{\mathrm{c}}}+\frac{G_{\mathrm{s}}}{G_{\mathrm{s}}^{\mathrm{c}}}=1
$$

Table 2 shows the cohesive properties for both adhesives which were determined from the data of Table 1, considering the average values of the experiments.

\section{Results and discussion}

It should be emphasized at this stage that fracture for all tested specimens occurred by cohesive crack propagation in the adhesive layer. However, for some repair configurations, plastic

Table 2. Properties of the adhesives Araldite ${ }^{\circledR}$ AV138 and 2015 for CZM modelling.

\begin{tabular}{lcc}
\hline Property & AV138 & 2015 \\
\hline Young's modulus, $E(\mathrm{GPa})$ & 4.89 & 1.85 \\
Shear modulus, $G(\mathrm{GPa})$ & 1.56 & 0.56 \\
Cohesive strength in tension, $t_{n}^{0}(\mathrm{MPa})$ & 39.45 & 21.63 \\
Cohesive strength in shear, $t^{0}(\mathrm{MPa})$ & 30.2 & 17.9 \\
Fracture toughness in gtension, $G_{n}^{\mathrm{c}}(\mathrm{N} / \mathrm{mm})$ & 0.20 & 0.43 \\
Fracture toughness in shear, $G^{\mathrm{c}}{ }_{n}(\mathrm{~N} / \mathrm{mm})$ & 0.38 & \\
\multicolumn{1}{c}{} & & \\
\hline
\end{tabular}


deformation of the adherends and/or patches took place. For all the repair configurations, the FE fracture modes managed to accurately replicate the experiments.

Detailed description of the load-displacement $(P-\delta)$ curves and visualizations of the fractures is only provided for the Araldite ${ }^{\circledR} 2015$ which is sufficient for validation purposes.

\subsection{Adhesive Araldite ${ }^{\circledR} 2015$}

For the SS repairs, the experimental data showed that, for $L_{O}=10 \mathrm{~mm}$, plastic deformation of the adherends or patches did not occur (Figure 5 shows the FE fracture for this condition; SDEG represents the stiffness degradation of the cohesive elements, with SDEG $=0$ related to undamaged material and SDG $=1$ to complete failure). However, for $L_{O}=20$ and $30 \mathrm{~mm}$ the loads sustained by the specimens were enough to cause plastic deformation of the patches, resulting in a premature failure of the adhesive layer (Figure 6 reports this behaviour for the $L_{\mathrm{O}}=30 \mathrm{~mm}$ SS repair; the onset of patch yielding occurred at $6400 \mathrm{~N}$ ). Figure 7 plots the experimental $P-\delta$ curves for the SS repairs with $L_{O}=30 \mathrm{~mm}$ and without embedded (a) and with embedded (b) patches, respectively. These $P-\delta$ curves show an approximately linear behaviour up to $\approx 6000 \mathrm{~N}$, followed by a constant load up to failure (corresponding to patch yielding). For the DS repairs, no plasticity was found in the adherends or patches, either for embedded or for non-embedded patches (FE failure mode in Figure 8 for embedded patches with $L_{O}=10 \mathrm{~mm}$ ), except for the $L_{\mathrm{O}}=20$ and $30 \mathrm{~mm}$ embedded patch repairs, which endured premature adherend yielding because the thickness of the aluminium adherends in the overlap

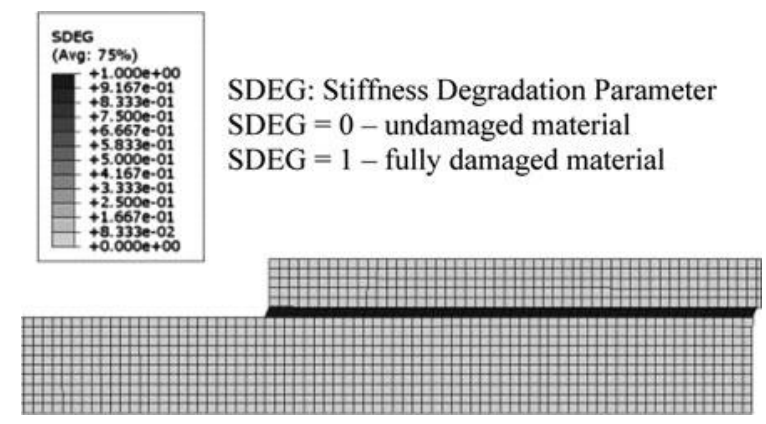

Figure 5. FE fracture for the SS repair with $L_{\mathrm{O}}=10 \mathrm{~mm}$ and no embedded patch.

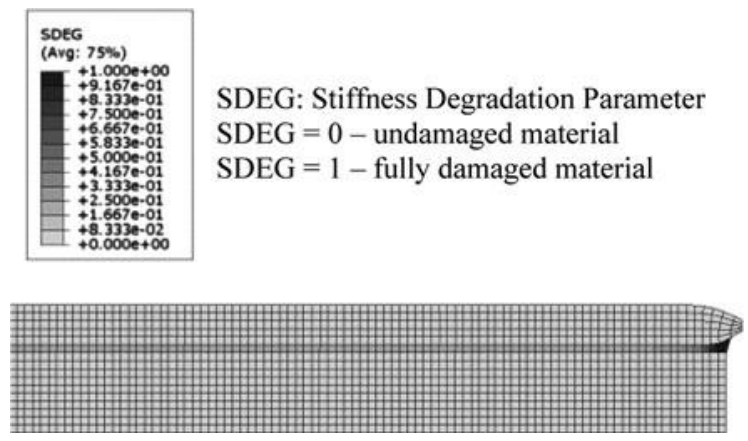

Figure 6. FE fracture for the SS repair with $L_{\mathrm{O}}=30 \mathrm{~mm}$ and no embedded patch. 
(a)

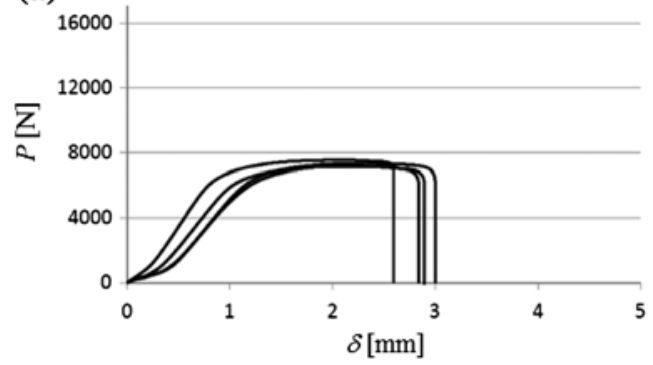

(b)

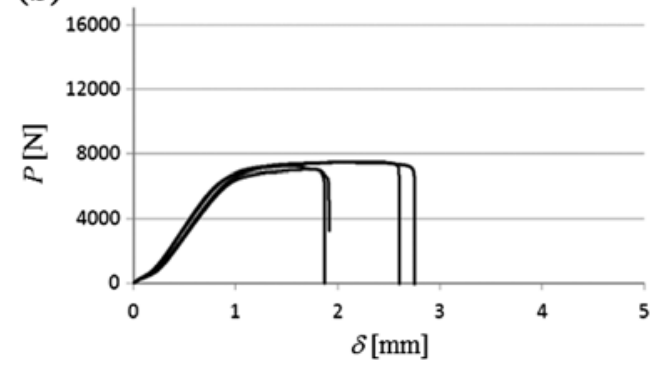

Figure 7. Load-displacement $P-\delta$ curves for the SS repairs without embedded (a) and with embedded (b) patch for the Araldite ${ }^{\circledR} 2015\left(L_{\mathrm{O}}=30 \mathrm{~mm}\right)$.

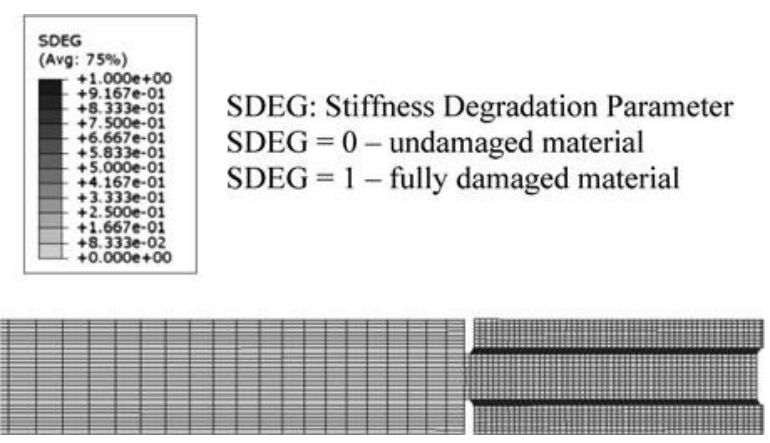

Figure 8. FE fracture for the DS repair with $L_{\mathrm{O}}=10 \mathrm{~mm}$ and embedded patches.

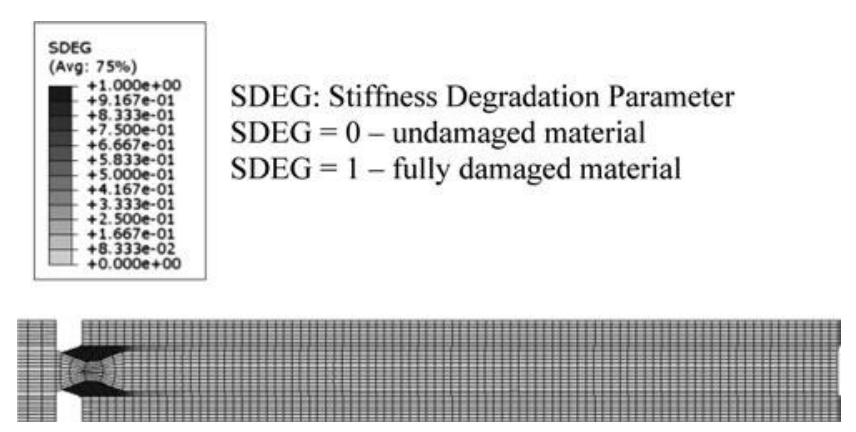

Figure 9. FE fracture for the DS repair with $L_{\mathrm{O}}=30 \mathrm{~mm}$ and embedded patches.

zone is only $1.6 \mathrm{~mm}$, reducing the repairs strength (Figure 9 shows this occurrence for $L_{\mathrm{O}}=30 \mathrm{~mm}$; initiation of adherend yielding started at $12,800 \mathrm{~N}$ ). Figure 10 plots the $P-\delta$ curves for the DS repairs with $L_{\mathrm{O}}=30 \mathrm{~mm}$ and without embedded (a) and with embedded (b) patches, respectively. In the first case, (Figure 10(a)), the maximum load $\left(P_{\mathrm{m}}\right)$ was $\approx 16,000 \mathrm{~N}$. For the DS repairs with embedded patches, (Figure 10(b)), the adherends yielding reduced $P_{\mathrm{m}}$ to $\approx 13,000 \mathrm{~N}$, by inducing premature crack propagation in the adhesive layer.

The test and FE values of $P_{\mathrm{m}}$ and deviations for the different values of $L_{\mathrm{O}}$ are presented in Figure 11(a) for the SS repairs. Results show a reduced scatter between 
(a)

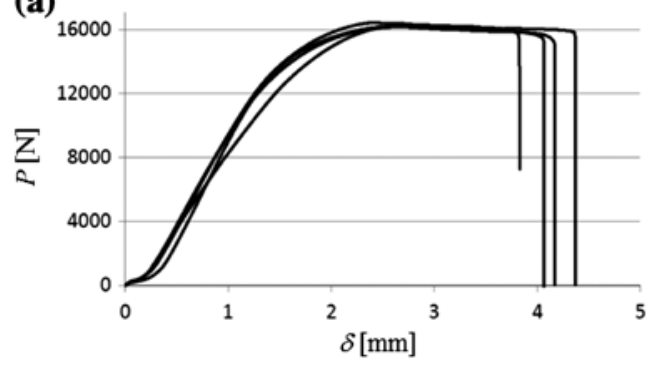

(b)

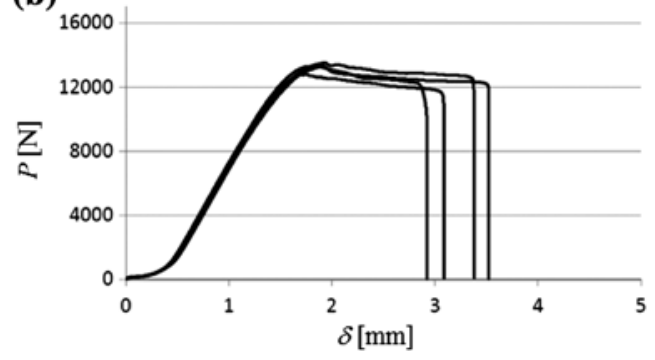

Figure 10. Load-displacement $P-\delta$ curves for the DS repairs without embedded (a) and with embedded (b) patches for the Araldite ${ }^{\circledR} 2015\left(L_{O}=30 \mathrm{~mm}\right)$.
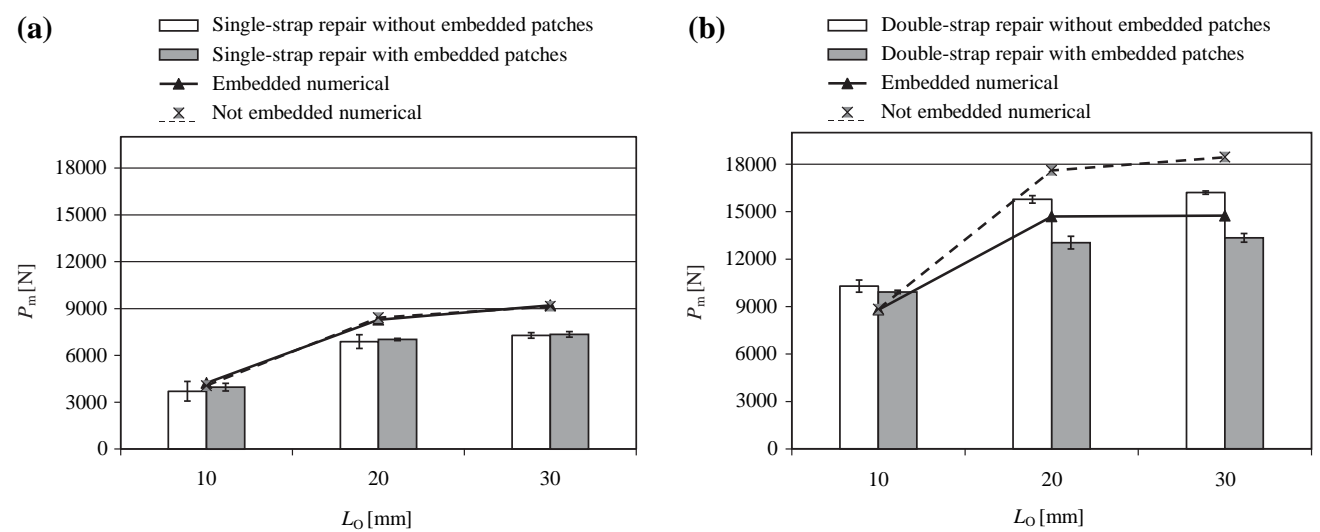

Figure 11. Experimental and FE (numerical) values of $P_{\mathrm{m}}$ for the SS (a) and DS (b) repairs with and without embedded patches (Araldite® 2015).

specimens with the same repair configuration. The experimental data also showed that increasing $L_{O}$ yields a strength improvement from $L_{\mathrm{O}}=10$ to $20 \mathrm{~mm}$, but above this value of $L_{\mathrm{O}}$ a steady-state value of $P_{\mathrm{m}}$ is achieved, because this corresponds to the yield limit of the patch which triggers the cohesive failure of the adhesive. Apart from this fact, a nonproportional strength improvement in bonded joints/repairs generally occurs with $L_{O}$ because of increasing differential straining of the adherends with the increase in $L_{\mathrm{O}}$, due to the larger loads sustained. In fact, whilst shear stress gradients are not important for small values of $L_{\mathrm{O}}$, they gradually increase with this quantity, owing to the increasing gradient of longitudinal strains in the adherends along the overlap [45]. Actually, the adh- erends are progressively loaded from their free overlap edge towards the other overlap edge. Since this gradient increases with $L_{O}$ due to the increase in the transmitted loads, as $L_{O}$ increases shear peak stresses at the overlap edges increase as well [2]. Regarding the embedded technique, for the SS repairs, it provides the typical aerodynamic and aes- thetic advantages without compromising the global repair strength, and thus, it can be rec- ommended. From Figure 11(a) it is possible to observe the FE results surpass the real behaviour of the repairs (maximum of 20.4\%), but these accurately modelled the strength improvement with $L_{\mathrm{O}}$. The equivalency between the non-embedded and embedded results is also captured in the simulations. 
An equivalent analysis was performed for the DS repair condition (Figure 11(b)). DS repairs are typically under symmetric loads, which eliminate the transverse flexure characteristic of SS repairs [2]. However, the patches are still under flexure, leading to peel peak stresses of smaller magnitude in the adherends. Compared to the corresponding SS values (Figure 11 (a)), DS results show that $P_{\mathrm{m}}$ is more than two times of the SS repairs strength, despite having twice the bonding area. This is justified by the smaller magnitude of peel stresses owing to the absence of the adherends deflection, and also due to the reduction in shear peak stresses at the overlap edges caused by the reduction in differential shearing between the adherend and patches [2]. The increase in $P_{\mathrm{m}}$ with $L_{\mathrm{O}}$ is also not proportional for the DS configuration, with a maximum efficiency being found near $L_{\mathrm{O}}=20 \mathrm{~mm}$ and no improvement for $L_{\mathrm{O}}=30 \mathrm{~mm}$. For the non-embedded patch repairs, this occurs at a $P_{\mathrm{m}}$ value of $\approx 16,000 \mathrm{~N}$ and it can be explained by the patches yielding above $L_{O}=20 \mathrm{~mm}$. However, for the DS repairs, the embedded configuration has shown to reduce $P_{\mathrm{m}}$ because of premature adherends yielding, and therefore, it is not recommended for the tested conditions. The reported reduction (maximum of $17.7 \%$ for $L_{O}=30 \mathrm{~mm}$ ) is related to the reduced adherend thickness in the overlap region $(1.6 \mathrm{~mm}$, Figure 1) because of the thickness reduction at both adherend faces. This promotes the adherend yielding and plasticization (at $\approx 13,000 \mathrm{~N}$ ) before the patch yielding (at $\approx 16,000 \mathrm{~N}$ ) observed for the non-embedded patch repairs, which promoted the onset of failure in the adhesive layer. The FE results consistently overpredicted $P_{\mathrm{m}}$ for $L_{\mathrm{O}}=20$ and $30 \mathrm{~mm}$ (maximum of $12.1 \%$ for $L_{\mathrm{O}}=30 \mathrm{~mm}$ ), but this could be expected, considering the use of a triangular law to model a ductile adhesive.

\subsection{Adhesive Araldite ${ }^{\circledR}$ AV138}

The experimental and FE results of the SS repairs showed no evidence of plasticity for $L_{\mathrm{O}}=10 \mathrm{~mm}$ (adherends or patches). For the $L_{\mathrm{O}}=20 \mathrm{~mm}$ repair with or without embedded patches, minor patch plasticization was found (although the value of $P_{\mathrm{m}}$ was slightly lower than for the equivalent repairs with Araldite ${ }^{\circledR}$ 2015). In a similar way to the Araldite ${ }^{\circledR} 2015$, the repairs with $L_{\mathrm{O}}=30 \mathrm{~mm}$ failed cohesively in the adhesive after substantial plastic patch deformation at the overlap ends, which resulted in a very limited strength improvement for this condition because of promoting failure in the adhesive. On the other hand, the DS repairs showed major adherend plasticization from $L_{\mathrm{O}}=20 \mathrm{~mm}$, which largely reduced the repairs strength compared to the non-embedded condition. For identical conditions, the repairs bonded with the adhesive Araldite ${ }^{\circledR}$ AV138 always showed smaller tensile displacements up to failure. As examples, Figure 12 shows the $P-\delta$ plots for the SS (a) and DS (b) repairs

(a)

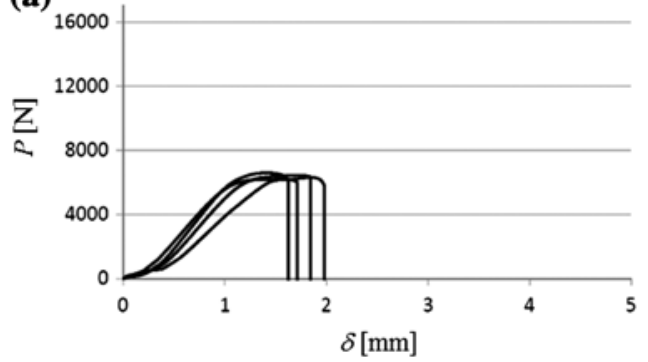

(b)

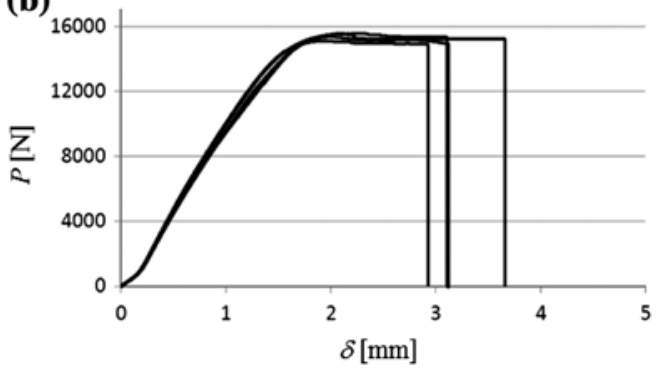

Figure 12. Load-displacement $P-\delta$ curves for the SS (a) and DS (b) repairs without embedded patches for the Araldite ${ }^{\circledR} \operatorname{AV} 138\left(L_{0}=30 \mathrm{~mm}\right)$. 
without embedded patches for the Araldite ${ }^{\circledR}$ AV138 $\left(L_{O}=30 \mathrm{~mm}\right)$, which can be compared with Figure 7(a) and Figure 10(a), respectively.

Figure 13(a) reports the experimental and FE values of $P_{\mathrm{m}}$ and deviations for the SS repairs with different values of $L_{0}$. Similarly to previous results for the Araldite ${ }^{\circledR} 2015$, specimens of the same configuration evidenced repeatability in the value of $P_{\mathrm{m}}$. In accordance with the aforementioned fracture modes, results showed a major improvement in $P_{\mathrm{m}}$ from $L_{\mathrm{O}}=10$ to $20 \mathrm{~mm}$ and, due to the beginning of the patch plasticization, a negligible improvement between $L_{\mathrm{O}}=20$ and $30 \mathrm{~mm}$. This event took place at approximately $6000 \mathrm{~N}$, identically to the Araldite ${ }^{\circledR} 2015$. The embedded repairs with identical geometry showed a smaller value of $P_{\mathrm{m}}$ for the entire range of $L_{\mathrm{O}}$ tested, although the difference was not too significant (maximum of $16.6 \%$ for the $L_{O}=10 \mathrm{~mm}$ ). These results go against the Araldite ${ }^{\circ} 2015$ equivalents, in which the opposite scenario was found. This is related to the sensitivity of brittle adhesives to increased peak stresses [38]. Depending on the application, the importance of aerodynamics and aesthetics may lead the designer to opt for embedding the patches. The numerical results showed an acceptable prediction, capturing the experimental trends with $L_{\mathrm{O}}$ and difference between the two configurations, although the predictions for non-embedded condition slightly surpassed the experimental results (maximum of $18.4 \%$ for $L_{\mathrm{O}}=30 \mathrm{~mm}$ ).

The DS repair results are presented in Figure 13(b). Identically to the Araldite ${ }^{\circledR} 2015$, when compared to the SS equivalent values (Figure 13(a))), DS repairs overcome the double of the SS repairs strength, reasoning for which was already discussed. For these specific repairs, the differences between the three tested values of $L_{O}$ were smaller than for the Araldite ${ }^{\circledR}$ 2015. This was due to the higher loads attained and also because of the adhesive brittleness, which makes the value of $P_{\mathrm{m}}$ even more dependent on the plasticization onset of the adherends or patches that exists for $L_{O}=10 \mathrm{~mm}$ and turns more important for bigger $L_{\mathrm{O}}$ values. In this specific case, for the repairs without embedded patches, a repair with $L_{O}=30 \mathrm{~mm}$ would actually have a small benefit over $L_{O}=10 \mathrm{~mm}$. The embedded repair results gave a smaller value of $P_{\mathrm{m}}$ for all the tested values of $L_{\mathrm{O}}$, although with a much bigger difference than for the Araldite ${ }^{\circledR}$ 2015, on account of the higher sensitivity of the Araldite ${ }^{\circledR}$ AV138 to the higher deformation of the adherends derived from their smaller thickness (due to the adhesive brittleness). Based on these results, the patch embedding procedure is not recommended for DS repairs. The FE predictions managed to fairly capture the test trends and differences between the two repair configurations, although there was a tendency to overpredict the results (maximum derivation of $18.6 \%$ for $L_{O}=20 \mathrm{~mm}$ ).

(a)

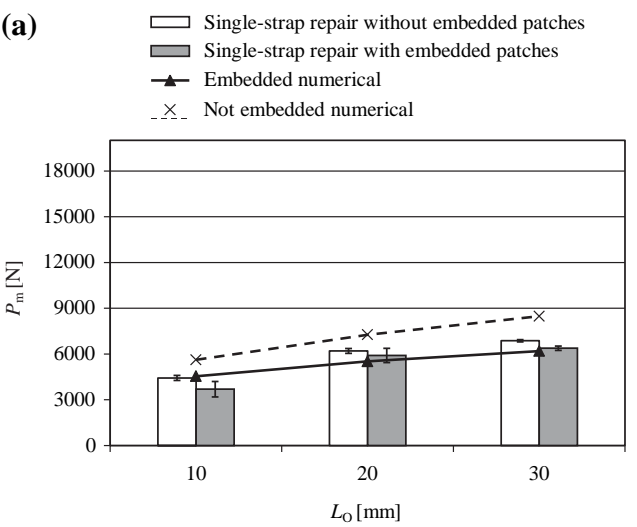

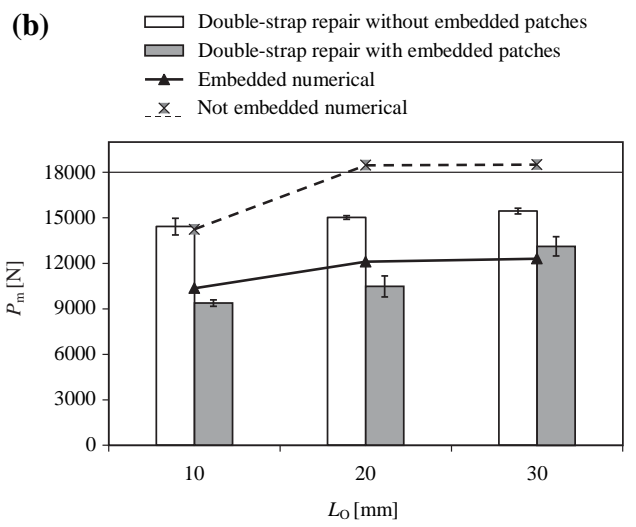

Figure 13. Experimental and FE (numerical) values of $P_{\mathrm{m}}$ for the SS (a) and DS (b) repairs with and without embedded patches (Araldite®AV138). 


\section{Conclusions}

In this work standard SS and DS repairs, and also with the embedded patches in the adherends, were tested under tension for two adhesives and three values of $L_{O}(10,20$ and $30 \mathrm{~mm}$ ). Regarding the FE predictions, although some variations from the experiments occurred, the experimental tendencies and relative influence of each repair configuration were accurately modelled. The main design-related conclusions drawn from this work are described in the following, although these should not be separated from the specific set of geometrical and material conditions selected for the analysis.

DS repairs have a higher strength than the SS repairs: the increase in strength is more than $2 \times$ because of the suppression of peel stresses.

- The plastic deformation of the adherends and patches significantly reduces the repair efficiency.

- A good agreement was found between experimental and FE results regarding the failure modes and the strengths.

SS repairs:

- The repairs with and without embedded patches show similar values of $P_{\mathrm{m}}$.

- The strength improvement from $L_{O}=10$ to $20 \mathrm{~mm}$ is significant. However, for $L_{\mathrm{O}}=30 \mathrm{~mm}$ no further improvement in strength was found because of the large patch plasticization, which weakened the adhesive in the nearby regions.

- For identical geometric conditions, the repairs with the adhesive Araldite ${ }^{\circledR} 2015$ showed higher tensile displacements up to failure.

\section{DS repairs:}

A large strength improvement was found with $L_{O}$ for the Araldite ${ }^{\circledR}$ 2015, oppositely to the Araldite ${ }^{\circledR}$ AV138.

- For the DS repairs with embedded patches the adherends thickness in the overlap region is only $1.6 \mathrm{~mm}$. Under these conditions, the adherends undergo severe plastic deformations before patch plasticization, which highly reduces $P_{\mathrm{m}}$ for both adhesives.

- The $P_{\mathrm{m}}$ reduction by embedding the patches was more significant for the Araldite ${ }^{\circledR}$ AV138 because of the higher sensitivity to peak stresses, induced by its brittleness.

- For identical geometric conditions, the repairs with the adhesive Araldite ${ }^{\circledR} 2015$ also presented higher displacements up to failure, equally to SS repairs.

\section{References}

[1] Luo Q, Tong L. Fully-coupled nonlinear analysis of single lap adhesive joints. International Journal of Solids and Structures. 2007;44:2349-70.

[2] Campilho RDSG, de Moura MFSF, Domingues JJMS. Modelling single and double-lap repairs on composite materials. Composites Science and Technology. 2005;65:1948-58.

[3] Osnes H, Andersen A. Computational analysis of geometric nonlinear effects in adhesively bonded single lap joints. Composites Part B. 2003;34:417-27.

[4] Marques EAS, da Silva LFM. Joint strength optimization of adhesively bonded patches. Journal of Adhesion. 2008;84:915-34.

[5] Campilho RDSG., de Moura MFSF, Pinto AMG, Morais JJL, Domingues JJMS. Modelling the tensile fracture behaviour of CFRP scarf repairs. Composites Part B. 2009;40:149-57. 
[6] Adams RD, Peppiatt NA. Stress analysis of adhesive-bonded lap joints. Journal of Strain Analysis. 1974;9:185-96.

[7] Baker AA. Repair of cracked or defective metallic components with advanced fiber composites: an overview of Australian work. Composite Structure. 1984;2:153-81.

[8] Baker AA, Jones R. Bonded patch repair of aircraft structures. Dordrecht: Martinus Nijhoff; 1988.

[9] Zhang H, Motipalli J, Lam YC, Baker A. Engineering of an elastic large muscular vessel wall with pulsatile stimulation in bioreactor. Composites Part A. 1998;29:1464-72.

[10] da Silva LFM, and Öchsner A, editors. Modeling of adhesively bonded joints. Berlin: Springer; 2008.

[11] Semerdjiev S. Metal to metal adhesive bonding. London: Business Books; 1970.

[12] Sancaktar E, Kumar S. Selective use of rubber toughening to optimize lap-joint strength. Journal of Adhesion Science and Technology. 2000;14:1265-96.

[13] da Silva LFM, Adams RD. Techniques to reduce the peel stresses in adhesive joints with composites. International Journal of Adhesion and Adhesives. 2007;27:227-35.

[14] Temiz S. Application of bi-adhesive in double-strap joints subjected to bending moment. Journal of Adhesion Science and Technology. 2006;20:1547-60.

[15] Pires I, Quintino L, Durodola JF, Beevers A. Performance of bi-adhesive bonded aluminium lap joints. International Journal of Adhesion and Adhesives. 2003;23:215-23.

[16] Fitton MD, Broughton JG. Variable modulus adhesives: an approach to optimized joint performance. International Journal of Adhesion and Adhesives. 2005;25:329-36.

[17] da Silva LFM, Lopes MJCQ. Joint strength optimization by the mixed adhesive technique. International Journal of Adhesion and Adhesives. 2009;29:509-14.

[18] Ganesh VK, Choo TS. Modulus graded composite adherends for single-lap bonded joints. Journal of Composite Materials. 2002;36:1757-67.

[19] Pinto AMG, Magalhães AG, Campilho RDSG, de Moura MFSF, Baptista APM. Single-lap joints of similar and dissimilar adherends bonded with an acrylic adhesive. Journal of Adhesion. 2009;85:351-76.

[20] Tsai MY, Morton J. The effect of a spew fillet on adhesive stress distributions in laminated composite single-lap joints. Composite Structures. 1995;32:123-31.

[21] Ashcroft IA, Abdel Wahab MM, Crocombe AD, Hughes DJ, Shaw SJ. The effect of environment on the fatigue of bonded composite joints. Part I: testing and fractography. Composite Part A. 2001;32:45-58.

[22] Chaves FJP, da Silva LFM, de Castro PMST. Adhesively bonded T-joints in polyvinyl chloride windows. Journal of Materials: Design and Applications. 2008;222:159-74.

[23] Adams RD, Harris JA. The influence of local geometry on the strength of adhesive joints. International Journal of Adhesion and Adhesives. 1987;7:69-80.

[24] Dorn L, Liu W. The stress state and failure properties of adhesive-bonded plastic/metal joints. International Journal of Adhesion and Adhesives. 1993;13:21-31.

[25] Lang TP, Mallick PK. Effect of spew geometry on stresses in single lap adhesive joints. International Journal of Adhesion and Adhesives. 1998;18:167-77.

[26] Vallée T, Correia JR, Keller T. Probabilistic strength prediction for double lap joints composed of pultruded GFRP profiles - Part I: experimental and numerical investigations. Composites Science and Technology. 2006;66:1903-14.

[27] Vallée T, Tannert T, Murcia-Delso J, Quinn DJ. Influence of stress-reduction methods on the strength of adhesively bonded joints composed of orthotropic brittle adherends. International Journal of Adhesion and Adhesives. 2010;30:583-94.

[28] Cheuk PT, Tong L. Failure of adhesive bonded composite lap shear joints with embedded precrack. Composites Science and Technology. 2002;62:1079-95. 
[29] Rispler AR, Tong L, Steven GP, Wisnom MR. Shape optimization of adhesive fillets. International Journal of Adhesion and Adhesives. 2000;20:221-31.

[30] Adams RD, Atkins RW, Harris JA, Kinloch AJ. Stress analysis and failure properties of carbonfibre-reinforced-plastic/steel double-lap joints. Journal of Adhesion. 1986;20:29-53.

[31] Hildebrand M. Non-linear analysis and optimization of adhesively bonded single lap joints between fibre-reinforced plastics and metals. International Journal of Adhesion and Adhesives. 1994;14:2617.

[32] Sancaktar E, Lawry PO. Photoelastic study of the stress distribution in adhesively bonded joints with prebent adherends. Journal of Adhesion. 1980;11:233-41.

[33] Fessel G, Broughton JG, Fellows NA, Durodola JF, Hutchinson AR. Evaluation of different lapshear joint geometries for automotive applications. International Journal of Adhesion and Adhesives. 2007;27:574-83.

[34] Çitil Ş, Temiz Ş, Altun H, Özel A. Determination of mechanical properties of double-strap adhesive joints with an embedded patch. Journal of Adhesion Science and Technology. 2011;25:255567.

[35] Campilho RDSG, Banea MD, Pinto AMG, da Silva LFM, de Jesus AMP. Strength prediction of single and double-lap joints by standard and extended finite element modelling. International Journal of Adhesion and Adhesives. 2011;31:363-72.

[36] ASTM-E8M-04. Standard test methods for tension testing of metallic materials (Metric); 2004.

[37] da Silva LFM, da Silva RAM, Chousal JAG, Pinto AMG. Alternative methods to measure the adhesive shear displacement in the thick adherend shear test. Journal of Adhesion Science and Technology. 2008;22:15-29.

[38] Campilho RDSG, Pinto AMG, Banea MD, Silva RF, da Silva LFM. Strength improvement of adhesively-bonded joints using a reverse-bent geometry. Journal of Adhesion Science and Technology. 2011;25:2351-68.

[39] Goyal VK, Johnson ER, Goyal VK. Predictive strength-fracture model for composite bonded joints. Composite Structures. 2008;82:434-46.

[40] Campilho RDSG, de Moura MFSF, Ramantani DA, Morais JJL, Domingues JJMS. Tensile behaviour of three-dimensional carbon-epoxy adhesively bonded single- and double-strap repairs. International Journal of Adhesion and Adhesives. 2009;29:678-86.

[41] Campilho RDSG, de Moura MFSF, Ramantani DA, Morais JJL, Domingues JJMS. Buckling behaviour of carbon-epoxy adhesively-bonded scarf repairs. Journal of Adhesion Science and Technology. 2009;23:1493-513.

[42] Campilho RDSG, de Moura MFSF, Domingues JJMS. Using a cohesive damage model to predict the tensile behaviour of CFRP single-strap repairs. International Journal of Solids and Structures. 2008;45:1497-512.

[43] ABAQUS® HTML Documentation. Vélizy-Villacoublay Cedex, France: Dassault Systemes; 2009.

[44] Jing J, Gao F, Johnson J, Liang FZ, Williams RL, Qu J. Simulation of dynamic fracture along solderpad interfaces using a cohesive zone model. Engineering Failure Analysis. 2009;16:1579-86.

[45] Reis P, Antunes F, Ferreira JAM. Influence of superposition length on mechanical resistance of singlelap adhesive joints. Composite Structures. 2005;67:125-33. 